\title{
Evaluating Concepts Presented in a Geometric Dimensioning and Toleranc- ing Course
}

\section{Dr. Theodore J. Branoff, Illinois State University}

Dr. Branoff is a professor and chair of the Department of Technology at Illinois State University. He taught engineering graphics, computer-aided design, descriptive geometry, and instructional design courses in the College of Education at North Carolina State University from 1986-2014. He also worked for SiemensSwitchgear Division and for Measurement Group, Inc. Dr. Branoff's research interests include constraintbased solid modeling strategies and spatial visualization abilities in undergraduate students. He has conducted CAD and Geometric Dimensioning and Tolerancing workshops for both industry and education professionals. Dr. Branoff served as President of the International Society for Geometry and Graphics from 2009-2012. In 2013 he was elected into the Academy of Fellows of the ASEE, and in 2014 he received the Distinguished Service Award from the Engineering Design Graphics Division of ASEE. In April of 2015 Dr. Branoff received the Orthogonal Medal for distinguished service in graphic science from the Technology, Engineering \& Design Education faculty at North Carolina State University. 


\title{
Evaluating Concepts Presented in a Geometric Dimensioning and Tolerancing Course
}

\begin{abstract}
During the Fall 2016 semester a geometric dimensioning and tolerancing course was offered for the first time at Illinois State University. The course was offered again during the Fall 2017 semester. The course learning outcomes included symbol identification, identifying features with and without size, specifying GD\&T within given design scenarios, calculating virtual condition, determining advantages for different material condition modifiers, applying datum reference frames to designs, and demonstrating proper inspection set-ups and procedures for verifying geometric tolerances. A pretest was given at the beginning of each semester to assess students' prior knowledge. Other assessments later in the course (e.g., online quizzes, tests, and final exam) included parallel assessment items to those included on the pretest. This paper will outline the main topics and structure of the course, summarize some of the assessment data gathered during the Fall 2016 and 2017 semesters, and analyze student performance on concepts presented during both semesters.
\end{abstract}

\section{Introduction / Review of Literature}

Geometric dimensioning and tolerancing (GD\&T) is an unambiguous mathematical language that describes form, orientation, and location of part features within specified zones of tolerance [1]. Although the standards for dimensioning and tolerancing [2] were developed many years ago, GD\&T has not been a topic widely integrated into engineering programs. One reason for not including it in curricula is related to its importance relative to other topics. In addition, some of the misconceptions of GD\&T also contribute to its lack of presence in curricula [3]. When individuals are not prepared to apply GD\&T correctly, several things can happen [4]. These include:

- Parts appear to assemble and operate correctly, but in practice they fail in all aspects.

- Burden is placed on machinists by supplying them with bad information - and then placing blame on them when things do not work.

- The costs of parts increase.

- Incorrect specifications are placed on drawings, which force metrologists to interpret the correct meanings.

- Time and money are wasted, blame is placed on GD\&T, when the real problem is misuse.

More recently we have seen an increase in GD\&T publications related to engineering education and product definition [5], [6], [7], [8], [9]. These articles make an effort to reduce some of the misconceptions involved with GD\&T.

\section{Rationale for the Course}

Several things contributed to justifying a single course in GD\&T at Illinois State University. Since the main program objective is to prepare professionals who can integrate engineering principles with modern manufacturing technologies, it seemed natural that GD\&T concepts would be discussed at some level. The program advisory board confirmed the importance of 
adding this course in 2015, and the course was offered for the first time in the fall of 2016. Specific course objectives were outlined, and these were tied back to program level outcomes to satisfy accreditation standards. The Association for Technology, Management, and Applied Engineering has established standards for program excellence, and Standard 4 addresses program competency identification and validation:

Measurable competencies shall be identified, assessed and validated for each program/option. These competencies must closely relate to the general outcomes established for the program/option and validation shall be accomplished through a combination of external experts, an industrial advisory committee and, after the program is in operation, follow up studies of program graduates [10].

The Engineering Technology program at Illinois State University has six program outcomes. These outcomes are listed below. Activities in TEC333 address the last two program outcomes.

1. Interpret and apply basic concepts of materials science such as strength of materials, structural properties, conductivity, and mechanical properties. Perform various nondestructive and destructive materials testing procedures.

2. Analyze and apply basic electricity and electronic principles within the various manufacturing environments and applications such as industrial robots, controls, and other such systems.

3. Monitor and control manufacturing processes or other industrial systems.

4. Select appropriate manufacturing processes for product production applications such as forming, molding, separating, conditioning, joining, and finishing.

5. Utilize 2-D and 3-D computer-aided design systems to create drawings and models for products, machines, jigs, fixtures, and other mechanical devices used in manufacturing environments.

6. Read and interpret manufacturing documentation such as blue prints, technical drawings and diagrams, production plans, tooling plans, quality plans, and safety plans.

TEC333 also has specific course objectives. Upon successful completion of the course, students will be able to:

1. Identify geometric characteristic symbols and the other symbols associated with geometric dimensioning and tolerancing.

2. Identify features with size and features without size.

3. Specify limit dimensions.

4. Calculate virtual condition for features.

5. Determine the advantage of using different material condition modifiers.

6. Apply appropriate datum reference frames to designs.

7. Apply appropriate form, orientation, profile, runout, and location tolerances to designs.

8. Execute proper inspection set-ups and procedures for checking geometric tolerances.

\section{Outline of the Course}

TEC333 was designed to provide students an overview of the basic terminology used in GD\&T, opportunities to apply GD\&T in a design setting for modestly complex parts, activities where 
students apply GD\&T within a CAD environment, and laboratories where students inspect parts using calipers and coordinate measuring machines (CMM). There are two prerequisite courses to TEC333. The first prerequisite course is an introductory engineering graphics course which covers visualization sketching and constraint-based modeling using Autodesk ${ }^{\circledR}$ Inventor ${ }^{\circledR}$. The second prerequisite course covers engineering graphics drawing standards and part and assembly modeling using Siemens NX®. To accomplish the course objectives in TEC333, students complete a combination of workbook activities, CAD applications, caliper measuring activities, and coordinate measuring machine inspection activities. The main source for the content knowledge in the course is GeoTol Pro: A Practical Guide to Geometric Tolerancing per ASME $Y 14.5$ - 2009 [1]. This is a workbook style text that contains end-of-unit exercises geared toward industry professionals. Rather than collect workbooks each period, exercises are discussed in class and online quizzes of unit material are administered through the university's learning management system. In addition to the online quizzes, students GD\&T knowledge is assessed through two tests and a final exam. Table 1 displays the weekly topics.

\section{Assessment of Student Knowledge}

Students' entry level knowledge of GD\&T was assessed during the first day of class with a pretest. The topics included in the pretest covered a broad range of material in the course, but it was not intended to cover some of the course objectives associated with more applied materials. The pretest included items related to:

- identify current standards related to dimensioning and tolerancing

- given a drawing, label symbols (all around, countersink, datum feature, basic dimension, etc.)

- given a drawing, label the dimensions referring to a feature with size

- given a drawing, identify the MMC of a specified hole, the amount of tolerance allowed if a boss/hole is produced at a certain size, and label the datum reference frame origin

- given a drawing with a profile tolerance applied, identify the type of the profile tolerance (bilateral-equal, bilateral-unequal, unilateral-in, and unilateral-out)

- given a drawing, sketch datum feature symbols per descriptions

- given a drawing with position tolerances, calculate virtual sizes

- given a sentence description of a composite position tolerance, sketch the feature control frame

- given a nominal size, specified fit (e.g., RC2), and a fit table, write out the limit dimension for a hole and pin system

Figures $1 \& 2$ show example items from the pretest.

Table 2 maps the pretest items to other assessments in the course. Each assessment column displays the number of correct responses to that item. For example, pretest question 1 asked students to identify the current U.S. Standard for Dimensioning and Tolerancing. Only 12 students out of 31 total students responded correctly. The question was also asked on the first test and on one of the online quizzes. One student missed that question on the first test, and one student missed it on the online quiz. Blank cells indicate the pretest item was not assessed on that particular test, quiz or exam. 
Table 1. Outline of TEC333.

\begin{tabular}{|c|c|c|}
\hline Week & Topic & Assignment \\
\hline \multirow{2}{*}{1} & Orientation / Safety discussion & \\
\hline & Introduction to GD\&T & Quiz 1 \\
\hline \multirow{2}{*}{2} & Limit Dimensioning / Limits of Size & Quiz 2 \\
\hline & Lab Activity & LAB 1 - Measuring with calipers \\
\hline 3 & How the GD\&T System Works & Quiz 3 \\
\hline \multirow[b]{2}{*}{4} & NX Modeling & Review of NX commands. \\
\hline & Lab Activity & $\begin{array}{c}\text { LAB 2 }- \text { CMM Lab } \\
\text { LAB 3 }- \text { NX model \& drawing }\end{array}$ \\
\hline \multirow{2}{*}{5} & Position Tolerance Verification & $\begin{array}{c}\text { Quiz } 4 \\
\text { LAB 4 - Excel table for pos. ver. }\end{array}$ \\
\hline & Lab Activity & $\begin{array}{c}\text { LAB 5 - CMM Lab } \\
\text { LAB 6 }- \text { NX model \& drawing }\end{array}$ \\
\hline \multirow{2}{*}{6} & Production Plans and Virtual Condition & Quiz 5 \\
\hline & TEST \#1 & Review Readings \\
\hline \multirow[b]{2}{*}{7} & The Datum Reference Frame & Quiz 6 \\
\hline & Lab Activity & $\begin{array}{c}\text { LAB 7 - CMM Lab } \\
\text { LAB 8 - Functional Gage Activity }\end{array}$ \\
\hline \multirow{2}{*}{8} & Lab Activity & Continue Working on Labs \\
\hline & Form Tolerances & Quiz 7 \\
\hline \multirow{2}{*}{9} & Orientation Tolerances & Quiz 8 \\
\hline & Profile Tolerances & Quiz 9 \\
\hline \multirow[t]{2}{*}{10} & Lab Activity & $\begin{array}{l}\text { LAB } 9 \text { - CMM Lab, Checking Profile } \\
\text { LAB 10 - NX Lab }\end{array}$ \\
\hline & Datum Feature Modifiers & Quiz 10 \\
\hline \multirow{2}{*}{11} & TEST \#2 & Review Readings \\
\hline & Catch up day - ATMAE Conference & Work on assignments \\
\hline \multirow[t]{2}{*}{12} & $\begin{array}{l}\text { The Datum Reference Frame II - Targets Irregular } \\
\text { Surfaces }\end{array}$ & Quiz 11 \\
\hline & Lab Activity & LAB 11 - Casting Drawing \\
\hline \multirow[t]{2}{*}{13} & $\begin{array}{l}\text { The Datum Reference Frame III - Advanced } \\
\text { Concepts }\end{array}$ & $\begin{array}{c}\text { Quiz 12 } \\
\text { LAB 12 }\end{array}$ \\
\hline & Lab Activity & LAB 13 - Pattern of Holes as a Datum \\
\hline \multirow[b]{2}{*}{14} & Position Tolerances & Quiz 13 \\
\hline & Lab Activity & $\begin{array}{l}\text { LAB } 14 \text { - CMM Lab, Checking } \\
\text { Position }\end{array}$ \\
\hline \multirow{2}{*}{15} & Coaxial Controls & Quiz 14 \\
\hline & Fastener Formulas and Screw Threads & \\
\hline 16 & Final Exam & Review Readings \\
\hline
\end{tabular}


Datums - On the drawing below, apply/sketch datum feature symbols as specified.

15. Establish the right-hand face in the left-side view as datum feature A.

16. Establish the axis of the large hole as datum feature B.

17. Establish the center plane of the slot (.750-755) as datum feature $C$.

18. Establish the 4 hole pattern as datum feature $\mathrm{D}$ (axis and orientation plane of the features).

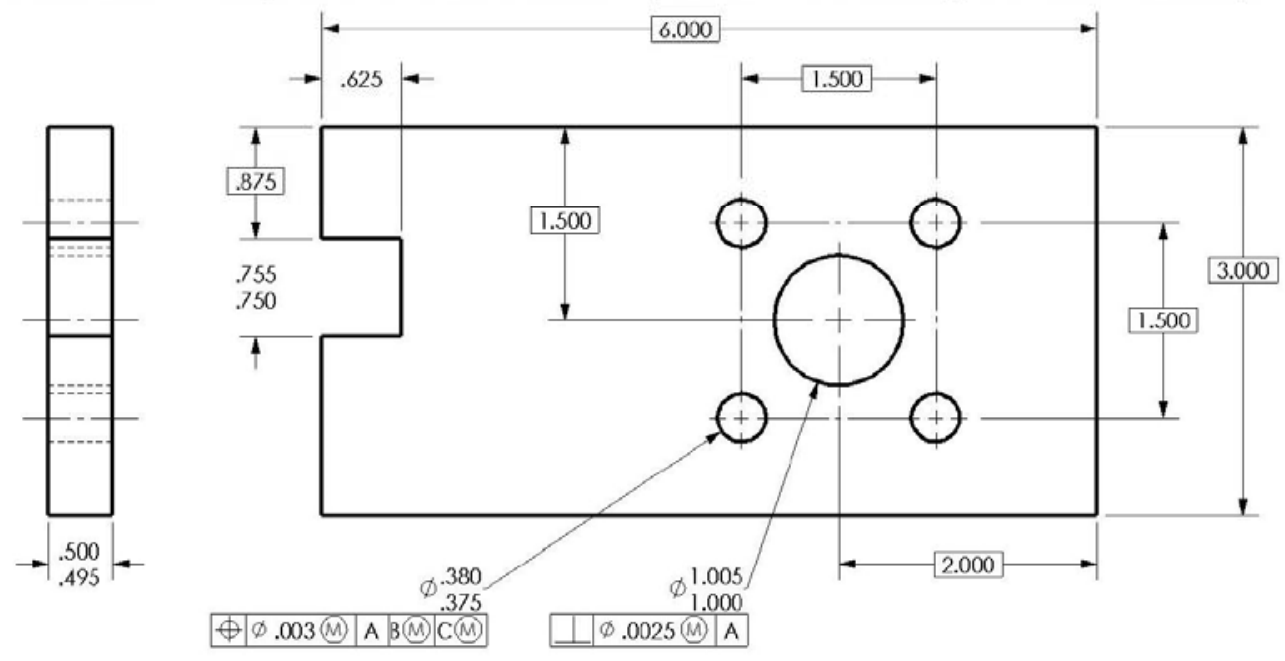

Figure 1. Example Item from Pretest - Sketching Datum Feature Symbols.

On the drawing below, calculate the virtual sizes for the identified features.

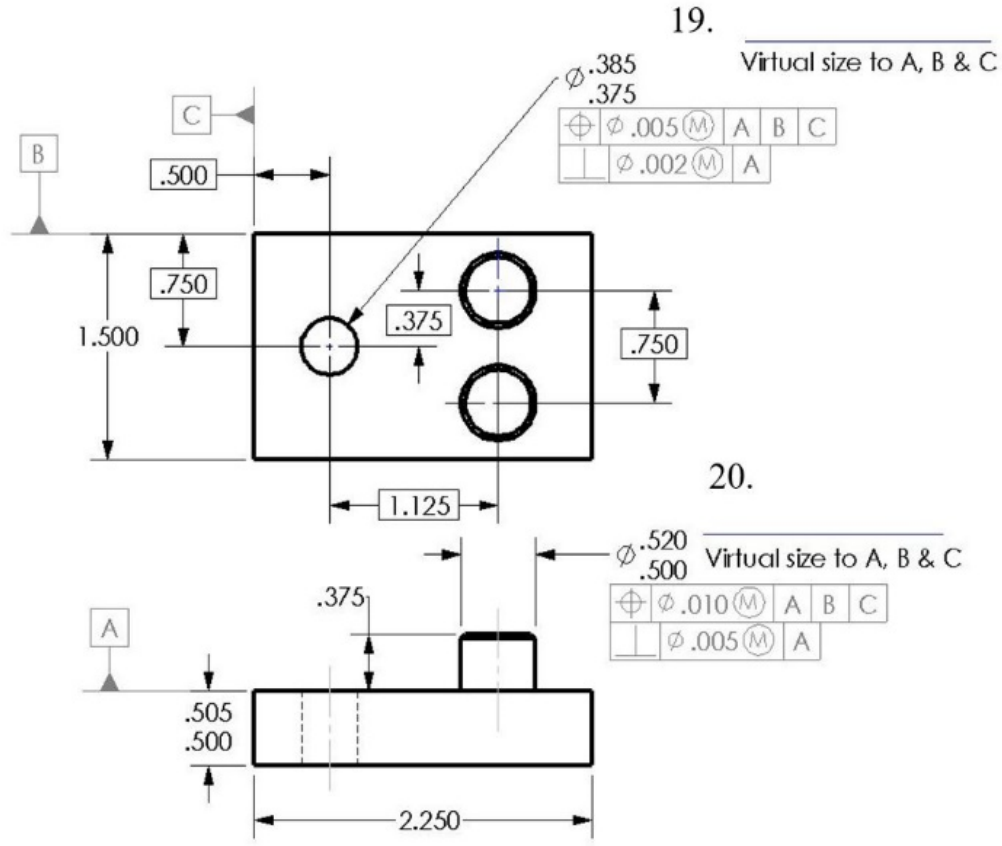

Figure 2. Example Item from Pretest - Determine Virtual Size/Condition. 
Table 2. Number of Correct Responses to Assessment Items Fall 2016 (12 students) \& Fall 2017 (19 students).

\begin{tabular}{|c|c|c|c|c|c|c|c|c|c|c|c|}
\hline \multirow[b]{2}{*}{$\begin{array}{c}\text { Pretest } \\
\text { Item }\end{array}$} & \multirow[b]{2}{*}{ Summary of question } & \multicolumn{2}{|c|}{ Pretest } & \multicolumn{2}{|c|}{ Test 1} & \multicolumn{2}{|c|}{ Test 2} & \multicolumn{2}{|c|}{ Quiz } & \multicolumn{2}{|c|}{ Exam } \\
\hline & & 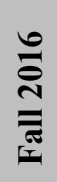 & 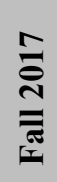 & 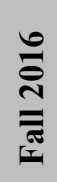 & 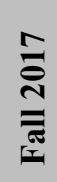 & 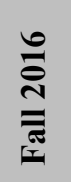 & 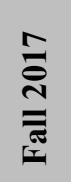 & 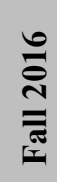 & $\frac{\sqrt[n]{\tilde{N}}}{\bar{\sigma}}$ & 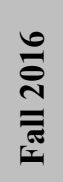 & 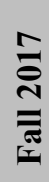 \\
\hline 1 & Identify current ASME Standard & 1 & 11 & 11 & 19 & & & 12 & 18 & & \\
\hline 2 & Identify all around symbol & 1 & 3 & 12 & 17 & & & 12 & 18 & & \\
\hline 3 & Identify countersink symbol & 12 & 15 & 12 & 19 & & & 12 & 19 & & \\
\hline 4 & Identify datum feature symbol & 6 & 11 & 10 & 18 & & & 12 & 17 & & \\
\hline 5 & Identify depth symbol & 11 & 17 & 12 & 19 & & & 12 & 19 & & \\
\hline 6 & Identify feature control frame & 12 & 15 & 12 & 19 & & & 12 & 17 & & \\
\hline 7 & Identify basic dimension & 9 & 16 & 12 & 19 & & & 12 & 19 & & \\
\hline 8 & Identifying features with size & 0 & 0 & 4 & 8 & & & 10 & 12 & & \\
\hline 9 & Calculating MMC of a boss/hole & 7 & 7 & 11 & 19 & & & 12 & 18 & & \\
\hline 10 & Position tolerance RFS & 0 & 5 & 7 & 12 & & & 12 & 18 & & \\
\hline 11 & Tolerance on a bolt circle - basic & 2 & 2 & 7 & 15 & & & 4 & 16 & & \\
\hline 12 & Position tolerance with MMC & 0 & 0 & 10 & 12 & & & 10 & 16 & 10 & 14 \\
\hline 13 & Label DRF origin & 0 & 2 & 10 & 13 & & & & & 5 & 3 \\
\hline 14 & Identify unilateral in profile tolerance & 3 & 6 & & & 10 & 12 & & & & \\
\hline 15 & Sketch DFS on surface A & 5 & 9 & & & 10 & 18 & 12 & 18 & 11 & 18 \\
\hline 16 & Sketch DFS large hole & 4 & 7 & & & 11 & 18 & & & & \\
\hline 17 & Sketch DFS center plane & 0 & 0 & & & 10 & 11 & & & & \\
\hline 18 & Sketch DFS pattern of holes & 5 & 6 & & & 12 & 19 & & & & \\
\hline 19 & Virtual size of a hole & 1 & 1 & 6 & 12 & & & 10 & 14 & & \\
\hline 20 & Virtual size of a cylinder & 1 & 0 & 9 & 14 & & & 10 & 16 & & \\
\hline 21 & Recognize 2 holes/cylinders as datum & 1 & 4 & & & 12 & 17 & 11 & 13 & 5 & 6 \\
\hline 22 & Recognize center plane as datum & 0 & 0 & & & 10 & 12 & 9 & 12 & 12 & 18 \\
\hline 23 & Recognize hole as datum & 3 & 6 & & & 5 & 8 & 5 & 12 & & \\
\hline 24 & Sketch FCF from description & 0 & 0 & 10 & 12 & & & & & & \\
\hline 25 & Look up limit from fit table & 1 & 1 & 6 & 3 & & & 11 & 16 & 8 & 5 \\
\hline
\end{tabular}

Bolded text indicates items where less than $75 \%$ of students answered correctly on a final assessment of the item.

\section{Results}

The data in Table 2 give a good indication of the topics students did and did not know at the beginning of the course. Only 3 students could not identify the symbol for depth on the pretest, and all but four students correctly identified the feature control frame and the countersink symbol. Most students could recognize a basic dimension on the pretest. Five of the pretest items 
were missed by all students. These included identifying features with size, determining the position tolerance when the maximum material modifier is present, sketching a datum feature symbol to represent a center plane, recognizing a center plane as a datum, and correctly sketching a feature control frame when given a sentence description.

The data also indicate how students progressed throughout the course on items assessed on the pretest. In general, it appears that students learned most of the concepts that were covered in the pretest since later assessments indicate higher levels of achievement. There are some exceptions where less than $75 \%$ of students answered correctly on a final assessment of that item (see bolded items in Table 2). These items include identifying features with and without size (Fall 2017), recognizing that a basic dimension does not have a tolerance (Fall 2016), calculating a position tolerance at MMC (Fall 2017), correctly labeling the datum reference frame origin on a given drawing (both semesters), identifying a "unilateral in" profile tolerance (Fall 2017), sketching a datum feature symbol to identify a center plane (Fall 2017), calculating the virtual size of a hole (Fall 2017), recognizing 2 holes or a single hole as a datum on a drawing (both semesters), sketching a feature control frame from a sentence description (Fall 2017), and correctly looking up limit dimensions on fit tables (both semesters). Figures 3-5 display examples for some of these items.

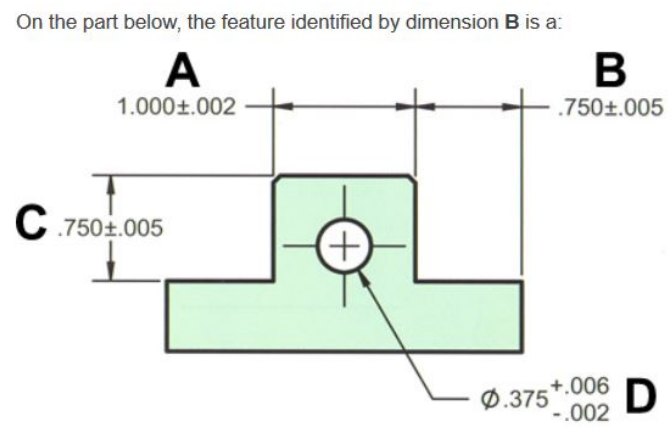

A. feature with size.

B. feature without size

Figure 3. Example Item from Quiz - Identifying a Feature Without Size [1].

21. Datum Reference Frames - Clearly label the origin of the datum reference frame in both views below (2 points).

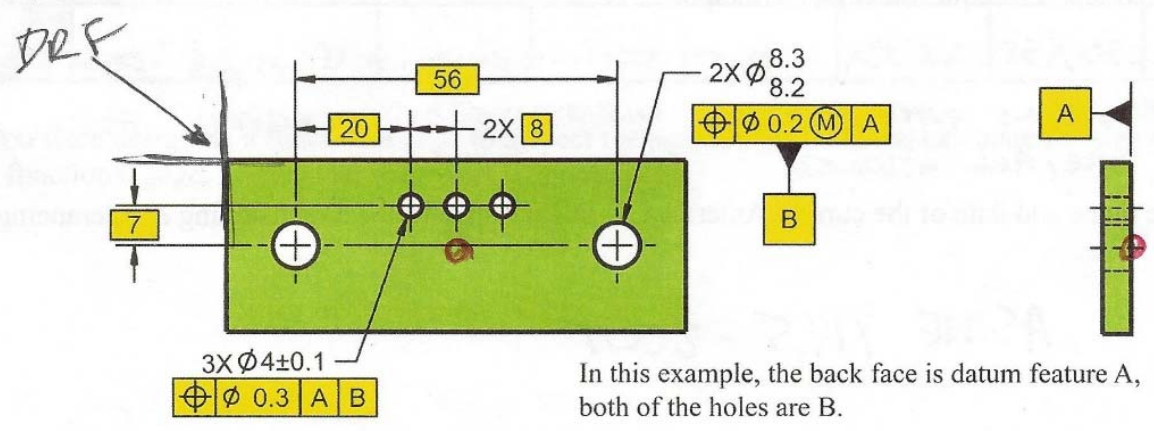

Figure 4. Incorrect Student Response from Exam - Label the DRF Origin [1]. 


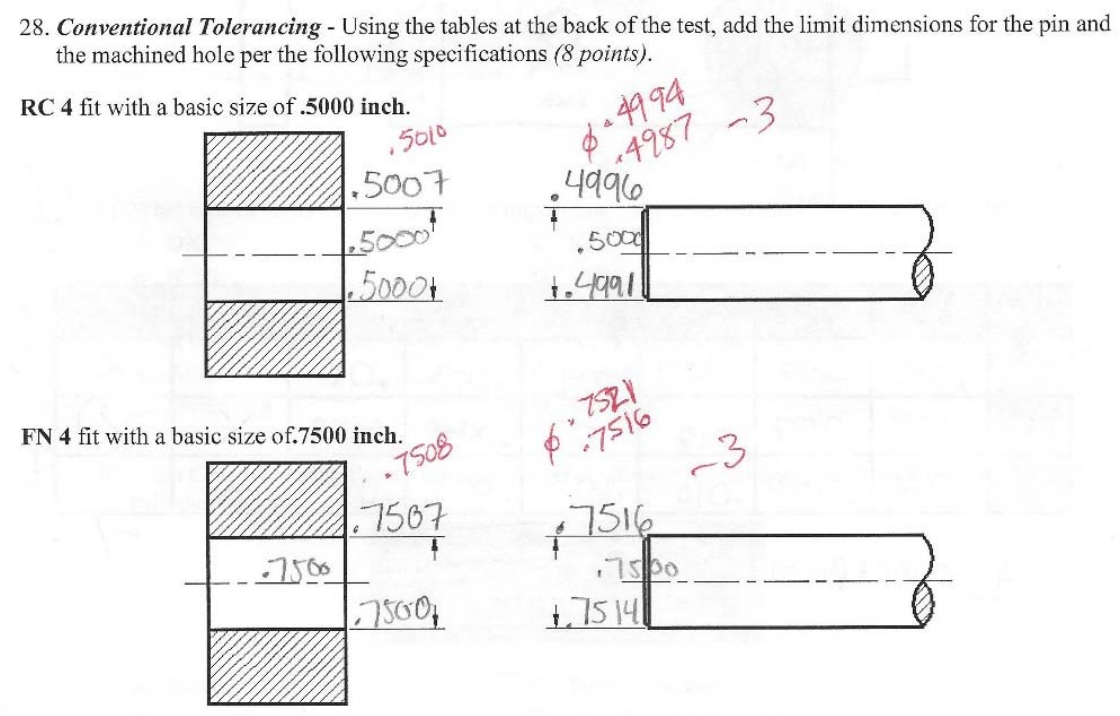

Figure 5. Incorrect Student Response from Test 1 - Looking Up Limit Dimensions.

\section{Conclusions and Future Research}

This paper only attempted to examine students' performance on pretest items in the course and then analyze how they performed on similar items later in the course. With the exception of completely understanding features with size, basic dimensions, calculating position with an MMC modifier, recognizing hole features as datums, locating the datum reference frame origin, and correctly interpreting fit tables, most students mastered the concepts presented on the pretest later in the course.

Several lessons can be learned from the data gathered over these two semesters. First, there are some areas where additional practice items need to be designed. One of these areas is understanding basic dimensions. Only about $42 \%$ of the students recognized that a basic dimension applied to bolt circle had no tolerance on Test 1 during the Fall 2016 semester. The rest of the students thought the general tolerance given on the drawing applied to that dimension. A second area in need of additional attention is recognizing hole features as datums and the implications of those datums on the location of the datum reference frame origin. It was obvious looking at the final exam data that only a few students could synthesize all of the given information correctly (Figure 4). One of the most disappointing areas of performance throughout the semester involved correctly looking up limit dimensions from fit tables. Performance was especially low when students were asked to look up limit dimensions from inch fit tables where values are given in thousandths of an inch. This practice is covered in multiple earlier courses, but it was evident students still do not understand the process. Students would benefit by completing extra practice problems in this area, but more importantly, faculty need to emphasize a process of thinking through the exercises. Future instruction will involve talking about generally accepted tolerances for metric and inch parts, asking students to make predictions about the correct values before going to a table to look up values, having students complete the exercise, and then discuss their answers within small groups. 
There are a couple areas that warrant future examination based on the data gathered over these two semesters. The first area is conducting a closer study of students' understanding of scale as it relates to sizes commonly encountered within a manufacturing environment. Many studies have been conducted in the sciences with students' understanding of nanoscale [11], [12], [13], [14]. Conducting similar studies with undergraduate students in engineering graphics and manufacturing will add important information to the body of knowledge in those areas.

Another potential area for future study within engineering graphics is examining students' understanding of a datum reference frame (DRF) specified on a drawing and their ability to model a 3D part with a consistent DRF origin. It was clear that students in TEC333 had difficulty recognizing the DRF when given a drawing with GD\&T. This was especially true when holes were used as datum features. Since one of the main tenants of GD\&T is to provide consistency through design, manufacturing, and inspection, conducting a closer examination of design intent within the drawing, constraint-based model, and the inspection method could provide useful data for improving instruction.

\section{References}

1. Neumann, S., \& Neumann, A. (2009). GeoTol Pro: A practical guide to Geometric Tolerancing. Longboat Key, FL: Technical Consultants, Inc.

2. ASME (2009). Dimensioning and Tolerancing, ASME Y14.5-2009. NY: American Society of Mechanical Engineers. 2009. ISBN 0-7918-3192-2.

3. Krulikowski, A. (2003). Nine myths about geometric dimensioning and tolerancing. Quality, 42 (10), 21-22.

4. Tandler, W. (2010). Making GD\&T work. Quality, 49 (2), 18-19.

5. Paige, M. A., \& Fu, K. (June, 2017). Spatial demonstration tools for teaching geometric dimensioning and tolerancing (GD\&T) to first-year undergraduate engineering students. Proceedings of the $124^{\text {th }}$ ASEE Annual Conference. Columbus, Ohio, June 25-28, 2017.

6. Yip-Hoi, D. M., \& Gill, D. (June, 2017). Use of model-based definition to support learning of GD\&T in manufacturing engineering curriculum. Proceedings of the $124^{\text {th }}$ ASEE Annual Conference. Columbus, Ohio, June 25-28, 2017.

7. Waldorf, D. J., \& Georgeou, T. M. (June, 2016). Geometric dimensioning and tolerancing (GD\&T) integration throughout a manufacturing engineering curriculum. Proceedings of the $123^{\text {rd }}$ ASEE Annual Conference. New Orleans, Louisiana, June 26-29, 2016.

8. Witherell, P., Herron, J., \& Ameta, G. (May, 2016). Towards annotations and product definitions for additive manufacturing. Proceedings of the $14^{\text {th }}$ CIRP Conference on Computer Aided Tolerancing, Gothenburg, Sweden. May 18-19, 2016.

9. Hewerdine, K. P., Leake, J. M. \& Hall, W. B. (June, 2011). Linking CAD and metrology to explain, demonstrate, and teach GD\&T. Proceedings of the $118^{\text {th }}$ ASEE Annual Conference. Vancouver, British Columbia, Canada, June 26-29, 2011.

10. Association of Technology, Management, and Applied Engineering (2017). 2017 Accreditation Handbook. Retrieved from https://c.ymcdn.com/sites/atmae.siteym.com/resource/resmgr/Docs/2017_Accreditation_Handbook.pdf.

11. Jones, M. G., Taylor, A., Minogue, J., Broadwell, B., Wiebe, E. N., \& Carter, G. (2007). Understanding scale: Powers of ten. Journal of Science Education and Technology, 16 (2), 191-202.

12. Jones, M. G., Andre, T., Superfine, R., \& Taylor, R. (2003). Learning at the nanoscale: The impact of students' use of remote microscopy on concepts of viruses, scale, and microscopy. Journal of Science Education and Technology, 40 (3), 303-322. 
13. Jones, M. G., Minogue, J., Tretter, T. R., Negishi, A., \& Taylor, R. (2005). Haptic augmentation of science instruction: Does touch matter? Science Education, 90 (1), 111-123.

14. Swarat, S., Light, G., Park, E. J., \&, Drane, D. (2011). A typology of undergraduate students' conceptions of size and scale: Identifying and characterizing conceptual variation. Journal of Research in Science Teaching, 48 (5), 512-533. 